\title{
The impact of carotid or intracranial atherosclerosis on perioperative stroke in patients undergoing open aortic arch surgery
}

Ken-ichi Imasaka, MD, PhD, Eiki Tayama, MD, PhD, and Yukihiro Tomita, MD, PhD

\section{ABSTRACT}

Objectives: This study aimed to clarify the impact of carotid or intracranial atherosclerosis on perioperative stroke in patients undergoing open aortic arch surgery.

Methods: Between 2008 and 2015, 200 consecutive patients underwent elective aortic arch surgery with selective antegrade cerebral perfusion and moderate hypothermic circulatory arrest. Nonselective screening for carotid or intracranial atherosclerosis was performed using carotid ultrasonography or magnetic resonance angiography. Carotid or intracranial atherosclerosis was classified as below moderate $(0 \%-49 \%$ stenosis $)$, moderate $(50 \%-69 \%)$, or severe $(70 \%-100 \%)$. In patients with moderate or severe stenosis, cerebral hemodynamics were evaluated using single-photon emission computed tomography with acetazolamide.

Results: None of the 37 patients undergoing preoperative single-photon emission computed tomography with acetazolamide had impaired cerebral hemodynamics. In-hospital mortality rate was 3.5\% (7/200). Postoperative neurologic morbidity included permanent stroke in 8 patients $(4.0 \%)$ and transient neurologic deficits in 27 patients $(14 \%)$. Permanent stroke occurred in 3 of 159 patients $(1.9 \%)$ with below moderate stenosis and 5 of 41 patients $(12.2 \%)$ with moderate or severe stenosis $(P=.008)$. Seven of 8 patients $(87.5 \%)$ with stroke experienced multiple atherothrombotic embolizations, and 1 patient experienced a stroke of unknown cause. In multivariate analysis, previous cerebrovascular accident (odds ratio, 5.0; 95\% confidence interval, 2.07-12.42; $P=.0004$ ) and shaggy aorta (odds ratio, $4.2 ; 95 \%$ confidence interval, $1.58-10.98 ; P=.0045)$ were significant determinants of neurologic morbidity.

Conclusions: Embolism was the major cause of permanent stroke in our patient population. Preoperative craniocervical and aortic screening may aid in modifying the operative strategy to reduce the occurrence of stroke. ( $\mathrm{J}$ Thorac Cardiovasc Surg 2017;153:1045-53)

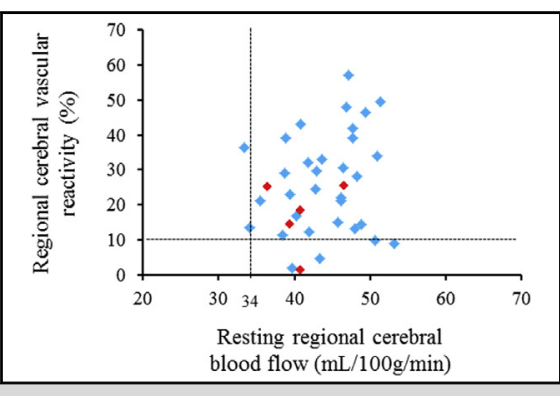

Brain hemodynamics in the right hemisphere of patients with craniocervical atherosclerosis.

\section{Central Message}

Our findings suggest that carotid or intracrania atherosclerosis rarely affects the incidence of hemodynamic ischemic stroke during OAAS.

\section{Perspective}

Few reports are available on the reliability of brain perfusion SPECT with acetazolamide to assess cerebral hemodynamics during OAAS Our findings suggest that craniocervical atherosclerosis rarely affects the incidence of hemodynamic ischemic stroke during surgery and that the cause of perioperative stroke is predominantly embolic.

\section{See Editorial Commentary page} 1054.
Stroke remains a devastating complication after cardiac surgery, with an incidence as high as $1 \%$ to $5 \% .{ }^{1}$ Moreover, perioperative stroke is approximately 4 times more common in open aortic arch surgery (OAAS) than in coronary

From the Department of Cardiovascular Surgery, Clinical Research Institute, National Hospital Organization Kyushu Medical Center, Fukuoka, Japan.

Read at The American Association for Thoracic Surgery Aortic Symposium 2016, New York, New York, May 12-13, 2016.

Received for publication June 3, 2016; revisions received Dec 9, 2016; accepted for publication Dec 22, 2016.

Address for reprints: Yukihiro Tomita, MD, PhD, Department of Cardiovascular Surgery, National Hospital Organization Kyushu Medical Center, 1-8-1 Jigyo-hama, Chuo-ku, Fukuoka 812-8582, Japan (E-mail: ytomita@kyumed.jp). $0022-5223 / \$ 36.00$

Copyright (c) 2017 by The American Association for Thoracic Surgery http://dx.doi.org/10.1016/j.jtcvs.2016.12.032 artery bypass grafting or valve surgery. ${ }^{2}$ Perioperative stroke in cardiovascular surgery is attributed to multiple causes, including embolism due to aortic manipulation or the sandblasting effect of flow through the aortic cannula against the aortic root, systemic inflammatory response to cardiopulmonary bypass (CPB), and hypoperfusion arising from significant carotid artery disease.

Scanning this QR code will take you to a supplemental video for the article.

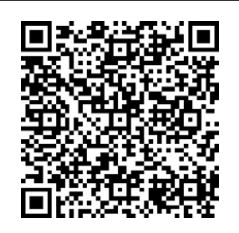




\section{Abbreviations and Acronyms \\ CIAD $=$ carotid or intracranial artery disease \\ $\mathrm{CPB}=$ cardiopulmonary bypass \\ HCA = hypothermic circulatory arrest \\ MRA = magnetic resonance angiography \\ OAAS $=$ open aortic arch surgery \\ PND = permanent neurologic deficit \\ $\mathrm{RCP}=$ retrograde cerebral perfusion \\ SACP = selective antegrade cerebral perfusion \\ SPECT $=$ single-photon emission computed tomography \\ $\mathrm{TND}=$ transient neurologic deficit}

Internal carotid artery stenosis of $50 \%$ or greater and $70 \%$ or greater occurs in $17 \%$ and $3.6 \%$ of patients undergoing aortic aneurysm reconstruction, respectively. ${ }^{4}$ However, the incidence of carotid disease in patients with thoracic aortic aneurysm remains unclear. Moreover, whether the presence of carotid or cerebral artery atherosclerosis affects the risk of perioperative stroke in patients undergoing OAAS remains poorly understood.

Cerebral blood flow is maintained over a wide range of cerebral pressures via cerebral autoregulation. ${ }^{5}$ However, impaired hemodynamic cerebral autoregulation in patients with atherosclerotic internal carotid artery or major intracranial artery occlusive disease is a risk factor for ischemic stroke. ${ }^{6}$ Cerebral hemodynamics are evaluated in physiologic states (ie, pulsatile flow, normothermia, and nonhemodilution) using brain perfusion single-photon emission computed tomography (SPECT) with acetazolamide or positron emission tomography. Nevertheless, little is known regarding the accuracy of cerebral hemodynamic analysis with these devices under nonphysiologic conditions that occur during OAAS (nonpulsatile flow, moderate hypothermia, selective cerebral perfusion, hypotension, and hemodilution). Previously, we revealed that in brain perfusion, SPECT with acetazolamide in obstructive carotid or intracranial artery disease (CIAD) had a negligible impact on the occurrence of hemodynamic ischemic stroke during elective cardiovascular surgery without selective cerebral perfusion. ${ }^{7}$ In the present study, we aimed to clarify whether obstructive CIAD is associated with the occurrence of perioperative stroke in OAAS.

\section{MATERIALS AND METHODS \\ Study Population}

This study was approved by the National Hospital Organization Kyushu Medical Center Institutional Review Board, and the need for individual consent was waived. Between October 2008 and October 2015, 332 consecutive patients underwent thoracic aortic surgery at our institute. From this cohort, we reviewed 200 patients undergoing elective OAAS with selective cerebral perfusion.

\section{Preoperative Screening of Carotid and Intracranial Cerebral Arteries}

Details regarding the preoperative screening of the carotid and intracranial cerebral arteries have been published. ${ }^{7}$ Briefly, carotid ultrasonography or magnetic resonance angiography (MRA) was performed in all 200 patients scheduled to undergo elective OAAS. During carotid ultrasonography screening, the degree of stenosis was calculated on the basis of methods outlined in the European Carotid Surgery Trial. ${ }^{8}$ Meanwhile, the degree of stenosis determined with MRA was calculated using the North American Symptomatic Carotid Endarterectomy Trial criteria. ${ }^{9}$ The calculated percent of stenosis was classified as mild $(30 \%-49 \%)$, moderate $(50 \%-69 \%)$, severe $(70 \%-99 \%)$, or occlusion. ${ }^{10}$

Cerebral hemodynamics were evaluated using brain perfusion SPECT with acetazolamide in patients with moderate stenosis, severe stenosis, or occlusion of the major arteries. The E.CAM SPECT apparatus (2-head SPECT system; Siemens, Erlangen, Germany) was used with ${ }^{99 \mathrm{~m}}$ Tc-ethyl cysteinate dimer as a tracer. By using brain perfusion SPECT with acetazolamide, resting regional cerebral blood flow and regional cerebrovascular reactivity were measured to evaluate cerebrovascular reserve capacity. Regional cerebrovascular reactivity was expressed according to the following equation: [(regional cerebral blood flow after acetazolamide challenge test - resting regional cerebral blood flow)/resting regional cerebral blood flow] $\times 100(\%)$. The lower limits of regional cerebral blood flow and regional cerebrovascular reactivity using brain perfusion SPECT were defined as $34 \mathrm{~mL} / 100 \mathrm{~g} / \mathrm{min}$ and $10 \%$, respectively. ${ }^{7}$ Impaired cerebral perfusion reserve was defined as resting regional cerebral blood flow $34 \mathrm{~mL} / 100 \mathrm{~g} / \mathrm{min}$ or less with cerebrovascular reactivity of $10 \%$ or less. In patients with impaired cerebral perfusion reserve, prophylactic carotid or cerebrovascular intervention for CIAD was taken into consideration to prevent hemodynamic ischemic stroke during OAAS.

\section{Surgical Procedures}

Patients received propofol, fentanyl, and sevoflurane for anesthesia and rocuronium for skeletal muscle relaxation. The right radial artery and unilateral femoral artery were cannulated for continuous blood pressure monitoring. In extended aortic arch replacement, patients were intubated with a double-lumen endotracheal tube and the distal anastomosis was performed under single-lung anesthesia. A transesophageal echocardiographic probe was used for confirmation of the diagnosis and assessment of cardiac function. The INVOS Cerebral Oximeter (Somanetics Corp, Troy, Mich) was attached on the forehead bilaterally to estimate intraoperative cerebral ischemia and cerebral oxygen desaturation during surgery. To avoid and reduce macroembolization, epiaortic ultrasonography of the ascending aorta was performed for all patients.

Arterial perfusion sites were bilateral axillary arteries and unilateral femoral artery in 161 patients $(80 \%)$, bilateral axillary arteries in 5 patients $(3 \%)$, unilateral axillary artery (right/left: $18 / 1)$ and unilateral femoral artery in 19 patients $(9 \%)$, right axillary artery in 13 patients $(7 \%)$, right axillary artery and ascending aortic artery in 1 patient $(0.5 \%)$, and ascending aortic artery in 1 patient $(0.5 \%)$. By using the axillary artery or femoral artery for arterial inflow, an 8-mm Hemashield Gold vascular graft (Maedox Medicals, Inc, Oakland, NJ) was interposed to perform systemic perfusion from CPB. In most instances, axillary inflow in addition to a graft was used to reduce perioperative stroke. ${ }^{11}$ Moreover, we preferred to use multiple arterial inflow sites to reduce the likelihood of perioperative stroke from embolic material by decreasing turbulent flow during CPB. ${ }^{12,13}$

After CPB was established with bicaval drainage, left ventricular venting and systemic cooling were initiated. The order of anastomosis of the ascending aorta or descending aorta was based on the surgeon's choice (proximal anastomosis first, $\mathrm{n}=164$; distal anastomosis first, $\mathrm{n}=36$ ). Adjunctive brain protection was performed via selective antegrade cerebral perfusion (SACP). As for a single-stage extended aortic arch repair, the L-incision approach ${ }^{14}$ or combined median sternotomy and left posterior thoracotomy was applied for total arch replacement. 
Proximal anastomosis first. After the heart was arrested with antegrade or retrograde cardioplegia, correction of the ascending aorta with or without the aortic root was undertaken, including any other required correction. After gradual cooling and when rectal temperature was approximately $25^{\circ} \mathrm{C}$ to $28^{\circ} \mathrm{C}$, circulatory arrest of the lower body and SACP were performed. Open distal anastomosis was performed during moderate hypothermic circulatory arrest (HCA) and SACP. During total arch replacement, an open distal anastomosis was completed using the elephant trunk technique. In most instances, cerebral perfusion was achieved by cannulation of the left common carotid artery and inflow via synthetic grafts of the bilateral axillary arteries. In patients without axillary artery inflow, cerebral perfusion was achieved by selective cannulation of the brachiocephalic artery, left common carotid artery, and left subclavian artery. The SACP was maintained at a perfusion rate of $10 \mathrm{~mL} / \mathrm{kg} / \mathrm{min}$ and controlled at 40 to $70 \mathrm{~mm} \mathrm{Hg}$ by regulating the arterial perfusion flow for brain protection. After systemic reperfusion, reconstruction of arch vessels in patients undergoing partial or total arch replacement was performed during rewarming. Isolated anastomoses of arch vessels with respective graft branches were performed at the National Hospital Organization Kyushu Medical Center. After the repair was completed, the patient was warmed to $36^{\circ} \mathrm{C}$ (rectal temperature) and weaned from CPB. Cardiac de-airing was carefully performed with transesophageal echocardiography before termination of CPB.

Distal anastomosis first. After gradual cooling and when rectal temperature was approximately $25^{\circ} \mathrm{C}$ to $28^{\circ} \mathrm{C}$, lower body circulatory arrest and SACP were performed. The heart was arrested with retrograde cardioplegia or selective antegrade cardioplegia. In patients undergoing concomitant heart surgery, heart procedures were performed during core cooling. Open distal anastomosis with the elephant trunk technique was performed with moderate HCA and SACP. After establishment of the distal anastomosis, lower body reperfusion was initiated through the femoral artery plus graft or 1 branch of the graft that was used for distal anastomosis. Proximal anastomosis of the graft was then completed, followed by coronary and systemic reperfusion. In patients undergoing partial arch replacement or total arch replacement, the aortic arch vessels were reconstructed. $\mathrm{CPB}$ weaning was performed in the same manner as previously mentioned.

\section{Definition of Clinical Parameters}

CIAD was defined as moderate stenosis, severe stenosis, or occlusion of the carotid or intracranial cerebral artery. Permanent neurologic deficit (PND) was defined as the presence of deficits including stroke or spinal cord ischemia that persisted at discharge. Moreover, PND was classified into permanent stroke versus paraplegia or paraparesis. On the other hand, transient neurologic deficit (TND) was defined as the occurrence of postoperative confusion, agitation, delirium, and prolonged obtundation without any new structural abnormality observed on imaging. ${ }^{15}$ Neurologic morbidity was defined as the occurrence of permanent stroke or TND. Shaggy aorta was defined as a fragile and speculated atheroma measuring at least $4 \mathrm{~mm}$ by enhanced computed tomography or epiaortic echocardiography in the ascending aorta or the arch, excluding the aneurysm itself. ${ }^{16,17}$ Partial arch replacement was defined as anastomosis of the brachiocephalic artery with the thoracic aortic surgical procedure. Meanwhile, total arch replacement was defined as the anastomosis of supra-aortic vessels (brachiocephalic artery, left common carotid artery, and left subclavian artery) with the thoracic aortic surgical procedure.

\section{Statistical Analysis}

Data were analyzed using the statistical analysis system software JMP 12.0.1 (SAS Institute Inc, Cary, NC). Categoric variables are expressed as frequencies and percentages, and continuous variables are expressed as means \pm standard deviations. Pearson's chi-square test or Fisher exact test was used to compare categoric variables. On the basis of methods previously described by Blackstone ${ }^{18}$ we used logistic regression analysis to determine risk factors associated with in-hospital mortality, permanent stroke, and neurologic morbidity. Categoric variables associated with at least 5 events and continuous variables were selected to investigate risk factors of respective surgical outcomes (Table 1). For in-hospital mortality and permanent stroke, univariate analysis alone was performed because of insufficient outcome events. For neurologic morbidity, 4 variables selected in ascending order of univariate $P$ value were entered into the multivariate analysis. Predictive accuracy of our multivariate models was assessed using the concordance index $c$.

\section{RESULTS}

\section{Preoperative Screening for Carotid or Intracranial Artery Disease, Patient Characteristics, and Surgical Data}

Table 1 reports patient characteristics and surgical data. After preoperative screening, 41 patients $(21 \%)$ were diagnosed with CIAD: $21(51 \%)$ with moderate ipsilateral stenosis (common carotid artery [ $\mathrm{n}=2]$, internal carotid artery $[\mathrm{n}=18]$, and middle cerebral artery $[\mathrm{n}=1]) ; 6(14 \%)$ with moderate bilateral stenosis (bilateral internal carotid artery $[\mathrm{n}=4]$ and ipsilateral internal carotid artery + contralateral common carotid artery $[\mathrm{n}=2]) ; 8(20 \%)$ with severe ipsilateral stenosis or occlusion (internal carotid artery $[\mathrm{n}=7]$ and vertebral artery $[n=1]) ; 2(5 \%)$ with severe ipsilateral stenosis and moderate contralateral stenosis (bilateral internal carotid artery $[\mathrm{n}=2])$; and $4(10 \%)$ with severe bilateral stenosis or occlusion (bilateral middle cerebral artery $[\mathrm{n}=1]$, bilateral internal carotid artery $[\mathrm{n}=1]$, ipsilateral internal carotid artery + contralateral common carotid artery $[\mathrm{n}=1]$, and ipsilateral internal carotid artery + contralateral posterior cerebral artery $[\mathrm{n}=1])$. Of 41 patients with CIAD, 37 (moderate stenosis [ $n=23$ ] and severe stenosis or occlusion [ $n=14]$ ) underwent preoperative brain perfusion SPECT with acetazolamide. Brain perfusion SPECT without acetazolamide was conducted in 2 patients whose resting regional cerebral blood flow values $(\mathrm{mL} / 100 \mathrm{~g} / \mathrm{min})$ were 50/48 (right/left) and 51/51, respectively. The other 2 patients did not undergo brain perfusion SPECT because of the decision of the attending physician. No patient with CIAD was diagnosed with impaired cerebral perfusion reserve on brain perfusion SPECT with or without acetazolamide challenge (Figure 1).

The causes of thoracic aortic aneurysm were atherosclerotic aneurysm $(n=139)$, chronic dissection $(n=49)$, annuloaortic ectasia $(n=10)$, and aortitis $(n=2)$. A total of 184 patients $(92 \%)$ underwent ascending aorta or aortic arch replacement through a median sternotomy. Meanwhile, 16 patients $(8 \%)$ underwent extended aortic arch replacement via $\mathrm{L}$-incision $(\mathrm{n}=15)$ or combined median sternotomy and left posterior lateral thoracotomy $(\mathrm{n}=1)$. Extensions of thoracic aortic surgery included ascending aortic replacement (including hemiarch replacement) in 31 patients $(16 \%)$, partial arch replacement in 16 patients $(8 \%)$, and total arch replacement in 153 patients $(76 \%)$. 
TABLE 1. Descriptive characteristics of the cohort, surgical data, and surgical outcomes

\begin{tabular}{|c|c|c|c|c|}
\hline Variables & $\begin{array}{c}\text { Overall } \\
(\mathbf{n}=\mathbf{2 0 0})\end{array}$ & $\begin{array}{l}\text { In-hospital mortality } \\
\qquad(\mathbf{n}=7)\end{array}$ & $\begin{array}{l}\text { Permanent stroke } \\
\qquad(\mathbf{n}=\mathbf{8})\end{array}$ & $\begin{array}{l}\text { Neurologic morbidity } \\
\qquad(\mathbf{n}=\mathbf{3 5})\end{array}$ \\
\hline Age (SD), $\mathrm{y}^{*}$ & $71(12)$ & & & \\
\hline Male $(\%)^{*}$ & $132(66)$ & 6 & 7 & 28 \\
\hline Obesity $\left(\mathrm{BMI}>26 \mathrm{~kg} / \mathrm{m}^{2}\right)(\%)^{*}$ & $26(13)$ & 1 & 1 & 5 \\
\hline Diabetes mellitus $(\%)^{*}$ & $26(13)$ & 1 & 2 & 4 \\
\hline Chronic renal dysfunction (serum creatinine $\geq 2.0 \mathrm{mg} / \mathrm{dL})(\%)^{*}$ & $10(5)$ & 1 & 1 & 2 \\
\hline COPD (FEV $1.0 \%<60 \%$ or drug use of prednisolone) $(\%) *$ & $40(20)$ & 1 & 3 & 12 \\
\hline Previous cerebrovascular accident $(\%)^{*}$ & $42(21)$ & 3 & 4 & 16 \\
\hline CIAD $(\%)^{*}$ & $41(21)$ & 2 & 5 & 13 \\
\hline Peripheral arterial disease (ankle brachial index $\leq 0.8)(\%)^{*}$ & $39(20)$ & 2 & 2 & 10 \\
\hline Shaggy aorta $(\%)^{*}$ & $37(19)$ & 3 & 6 & 16 \\
\hline \multicolumn{5}{|l|}{ Type of aneurysm $(\%)$} \\
\hline Atherosclerotic $(\%)^{*}$ & $139(70)$ & 4 & 6 & 27 \\
\hline Chronic aortic dissection $(\%)$ & $49(25)$ & 3 & 0 & 5 \\
\hline $\mathrm{AAE}+\mathrm{AR}(\%)$ & $10(5)$ & 0 & 2 & 3 \\
\hline Aortitis $(\%)$ & $2(1)$ & 0 & 0 & 0 \\
\hline Previous cardiac surgery via median sternotomy $(\%)^{*}$ & $7(4)$ & 0 & 0 & 1 \\
\hline Total arch replacement $(\%)^{*}$ & $153(76)$ & 7 & 6 & 29 \\
\hline Partial arch replacement $(\%)$ & $16(8)$ & 0 & 0 & 1 \\
\hline $\begin{array}{l}\text { Ascending aortic replacement (including hemiarch } \\
\text { replacement) }(\%)\end{array}$ & $31(16)$ & 0 & 2 & 5 \\
\hline Concomitant procedures $(\%)^{*}$ & $68(34)$ & 2 & 5 & 12 \\
\hline Aortic root repair $(\%)$ & $18(9)$ & 0 & 2 & 1 \\
\hline CABG $(\%)$ & $38(19)$ & 2 & 3 & 10 \\
\hline Valve surgery $(\%)$ & $19(10)$ & 0 & 0 & 1 \\
\hline $\begin{array}{l}\text { Extended aortic repair through L-incision or combined median } \\
\text { sternotomy and left posterior lateral thoracotomy }(\%)^{*}\end{array}$ & $16(8)$ & 1 & 4 & 9 \\
\hline Frozen elephant trunk technique $(\%)^{*}$ & $9(5)$ & 1 & 1 & 3 \\
\hline $\mathrm{CPB}$ time (SD), min* & $275(56)$ & & & \\
\hline Coronary ischemic time $(\mathrm{SD}), \mathrm{min}^{*}$ & $88(49)$ & & & \\
\hline HCA time (SD), min* & $65(21)$ & & & \\
\hline SACP time (SD), min* & $136(56)$ & & & \\
\hline Lowest rectal temperature $(\mathrm{SD}),{ }^{\circ} \mathrm{C}^{*}$ & $26(1)$ & & & \\
\hline Operation time $(\mathrm{SD}), \mathrm{min}^{*}$ & $614(120)$ & & & \\
\hline
\end{tabular}

Data represent mean \pm standard deviation or number (percentage). $S D$, Standard deviation; $B M I$, body mass index; $C O P D$, chronic obstructive pulmonary disease; $F E V_{1.0} \%$, forced expiratory volume 1 second percent; $C I A D$, carotid or intracranial artery disease; $A A E$, annuloaortic ectasia; $A R$, aortic valve regurgitation; $C A B G$, coronary artery bypass grafting; $C P B$, cardiopulmonary bypass; $H C A$, hypothermic circulatory arrest; $S A C P$, selective antegrade cerebral perfusion. *Represent variables used to determine risk factors of in-hospital mortality, permanent stroke, or neurologic morbidity.

Moreover, concomitant procedures included composite graft replacement (Bentall procedure) in 18 patients $(9 \%)$, coronary artery bypass grafting in 38 patients $(19 \%)$, and valve surgery in 19 patients $(10 \%)$. Nine patients $(5 \%)$ underwent total arch replacement with frozen elephant trunk procedures.

Shaggy aorta was present in 37 patients (19\%). A total of 19 patients $(51 \%)$ with shaggy aorta had CIAD $(P<.0001)$, and 11 patients $(30 \%)$ with shaggy aorta underwent total arch replacement through an L-incision or combined median sternotomy and left posterior lateral thoracotomy $(P<.0001)$.

\section{Operative Results}

Table 2 reports the operative outcomes. In-hospital mortality rate was $3.5 \%(n=7)$. The causes of death included multiple organ failure in 2 patients, perioperative myocardial infarction in 2 patients, systemic atheromatous embolization in 1 patient, mesenteric ischemia in 1 patient, and unknown cause in 1 patient. The overall incidence of PND and TND was $5.5 \%(n=11)$ and $14 \%(n=27)$, respectively. Moreover, the overall incidence of permanent stroke and paraplegia or paraparesis was $4.0 \%(\mathrm{n}=8)$ and $2.0 \%(\mathrm{n}=4)$, respectively. A total of $7(88 \%)$ of 8 patients with permanent stroke had multiple atherothrombotic embolizations, and the cause was unknown in the remaining patient (Table 3). Three (37.5\%) of 8 patients with permanent stroke died during the postoperative hospital stay, compared with $4(2.1 \%)$ of 192 patients without stroke $(P=.0008)$.

\section{Determinants of In-Hospital Mortality, Permanent Stroke, and Neurologic Morbidity}

Tables 4 and 5 list the risk factors of in-hospital mortality and permanent stroke determined by univariate analysis. 

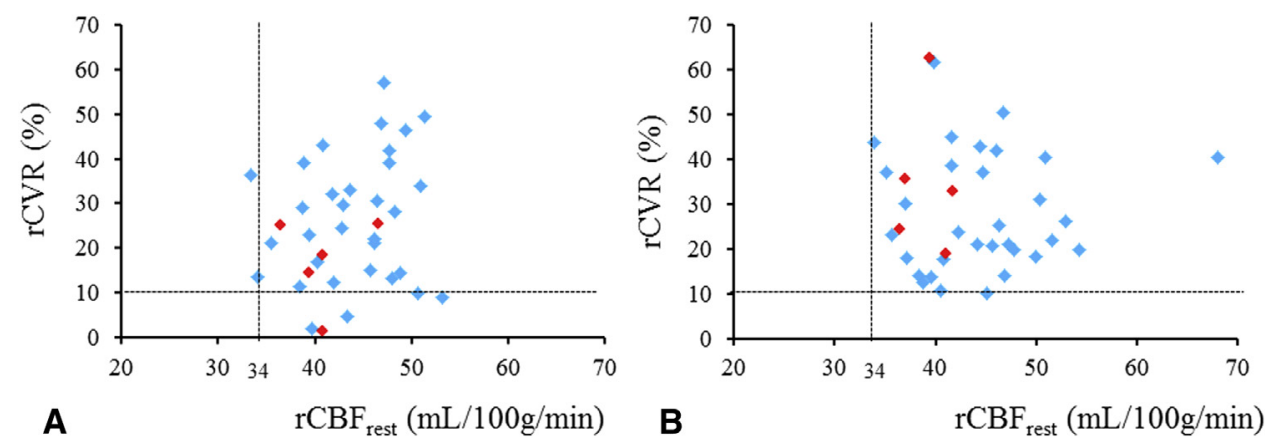

FIGURE 1. Resting regional cerebral blood flow and regional cerebral vascular reactivity using brain perfusion SPECT with acetazolamide in patients with CIAD: right hemisphere (A) and left hemisphere (B). Red and blue rhombi indicate patients with and without permanent stroke. Dashed vertical and horizontal lines indicate lower limits $(34 \mathrm{~mL} / 100 \mathrm{~g} / \mathrm{min}$ and $10 \%)$ of normal regional cerebral blood flow and regional cerebral vascular reactivity, respectively. $r C V R$, Regional cerebral vascular reactivity; $r C B F$, regional cerebral blood flow.

Multivariate analysis indicated that previous cerebrovascular accident and shaggy aorta were risk factors for neurologic morbidity (Table 6).

\section{DISCUSSION}

The major findings of the present study were as follows: (1) All patients with CIAD undergoing preoperative brain perfusion SPECT with acetazolamide were diagnosed with normal cerebral perfusion reserve; (2) no patient experienced hemodynamic ischemic stroke during OAAS; and (3) previous cerebrovascular accident and shaggy aorta were crucial determinants of neurologic morbidity in multivariate analysis.

Cerebral autoregulation plays a vital role in maintaining adequate cerebral blood flow in response to changes in cerebral perfusion pressure. ${ }^{5}$ However, impaired cerebral perfusion reserve, as indicated by increased oxygen extraction (ie, misery perfusion), carries a high risk of hemodynamic ischemic stroke in patients with steno-occlusive carotid or intracranial arteries. ${ }^{6}$ Imaging studies, including brain perfusion SPECT, positron emission tomography, and magnetic resonance imaging, have been used to assess of cerebral hemodynamics. ${ }^{19}$ Among them, brain perfusion SPECT with acetazolamide is widely used because it can evaluate cerebrovascular reactivity and cerebral perfusion, and it is highly sensitive for the detection of flow abnormalities. ${ }^{20}$ Previously, we reported that brain perfusion SPECT

TABLE 2. Operative outcomes

\begin{tabular}{lc}
\hline \multicolumn{1}{c}{ Variables } & n overall $=\mathbf{2 0 0}$ \\
\hline In-hospital mortality (\%) & $7(3.5)$ \\
PND (\%) & $11(5.5)$ \\
Permanent stroke & $8(4.0)$ \\
Paraplegia or paraparesis & $4(2.0)$ \\
TND (\%) & $27(14)$ \\
Perioperative myocardial infarction (\%) & $3(1.5)$ \\
Acute renal failure requiring hemofiltration $(\%)$ & $17(8.5)$ \\
Reexploration for bleeding (\%) & $8(4.0)$ \\
\hline
\end{tabular}

Data represent number (percentage). PND, Permanent neurologic deficit; TND, transient neurologic deficit. with acetazolamide can be used to screen patients at high risk of subsequent hemodynamic ischemic stroke under nonphysiologic conditions (ie, nonpulsatile flow, mild hypothermia, hypotension, and hemodilution) that occur during $\mathrm{CPB}$, as well as during physiologic conditions (ie, pulsatile flow, normothermia, and nonhemodilution). ${ }^{7}$ However, to the best of our knowledge, there are no reports concerning the accuracy of brain perfusion SPECT with acetazolamide in patients undergoing OAAS using nonpulsatile CPB with moderate HCA and SACP.

To date, many experimental and clinical studies have investigated brain protection and safe parameters for the optimization of cerebral autoregulation during OAAS, including optimum perfusion pressure, flow, temperature, $\mathrm{pH}$, hematocrit, and cannulation site. ${ }^{21,22}$ Neri and colleagues $^{21}$ showed that in 65 patients undergoing elective aortic arch surgery with deep HCA, SACP was superior to retrograde cerebral perfusion (RCP) or deep HCA without adjuncts for the preservation of postoperative cerebral autoregulation. Moreover, Spielvogel and colleagues ${ }^{22}$ suggested guidelines for SACP based on data from experimental and clinical studies. However, how obstructive CIAD negatively affects the technical refinements and safe parameters for brain protection in OAAS remains poorly understood. In the present study, we report for the first time that obstructive CIAD is rarely associated with the occurrence of hemodynamic ischemic stroke in OAAS or conventional cardiac surgery and that brain perfusion SPECT can screen patients at high risk of hemodynamic ischemic stroke during OAAS.

Carotid ultrasonography and MRA can be used to assess anatomic vascular lesions, and brain perfusion SPECT with acetazolamide can be used to quantitatively evaluate cerebral perfusion reserve. Urbanski and colleagues ${ }^{23}$ showed that all functional assessments using transcranial Doppler ultrasonography during unilateral cerebral perfusion in aortic arch surgery were normal, regardless of morphologic abnormalities of the circle of Willis observed by cranial computed tomographic angiography. These 
TABLE 3. Patients with stroke: Preoperative and intraoperative characteristics and surgical results

\begin{tabular}{|c|c|c|c|c|c|c|c|c|c|}
\hline Case & Age/sex & CIAD/stenosis & Type of aneurysm & $\begin{array}{l}\text { Surgical } \\
\text { approach }\end{array}$ & Surgery & $\begin{array}{l}\text { Frozen ET } \\
\text { technique }\end{array}$ & Cause & Site of stroke & Outcome \\
\hline 1 & $66 \mathrm{y} / \mathrm{M}$ & Right ICA/moderate & $\begin{array}{l}\text { Atherosclerotic } \\
\text { Shaggy aorta }\end{array}$ & $\begin{array}{l}\text { MS through } \\
\text { L-incision }\end{array}$ & TAR & $\mathrm{N}$ & $\mathrm{E}$ & $\begin{array}{l}\text { Right cerebellum and } \\
\text { occipital lobe, bilateral } \\
\text { frontal lobe }\end{array}$ & Alive \\
\hline 2 & $87 \mathrm{y} / \mathrm{M}$ & $\mathrm{N}$ & $\begin{array}{l}\text { Atherosclerotic } \\
\text { Shaggy aorta }\end{array}$ & MS & TAR & $\mathrm{Y}$ & Unknown & Unknown & Dead \\
\hline 3 & $82 \mathrm{y} / \mathrm{M}$ & Left ICA/moderate & $\begin{array}{l}\text { Atherosclerotic } \\
\text { Shaggy aorta }\end{array}$ & $\begin{array}{l}\text { MS through } \\
\text { L-incision }\end{array}$ & TAR & $\mathrm{N}$ & $\mathrm{E}$ & $\begin{array}{l}\text { Right frontal and parietal } \\
\text { and occipital lobe, } \\
\text { left parietal lobe }\end{array}$ & Dead \\
\hline 4 & $48 \mathrm{y} / \mathrm{M}$ & $\mathrm{N}$ & AAE, AR & MS & ARR & $\mathrm{N}$ & $\mathrm{E}$ & $\begin{array}{l}\text { Right basal ganglia and } \\
\text { cerebral cortex }\end{array}$ & Alive \\
\hline 5 & $76 \mathrm{y} / \mathrm{M}$ & $\begin{array}{l}\text { Bilateral ICA/severe } \\
\text { and moderate }\end{array}$ & $\begin{array}{l}\text { Atherosclerotic } \\
\text { Shaggy aorta }\end{array}$ & $\begin{array}{l}\text { MS through } \\
\text { L-incision }\end{array}$ & TAR & $\mathrm{N}$ & $\mathrm{E}$ & $\begin{array}{l}\text { Right occipital lobe, bilateral } \\
\text { frontal and parietal and } \\
\text { cerebellar lobe, Pons, } \\
\text { bilateral thalamus, T6-9 }\end{array}$ & Alive \\
\hline 6 & $71 \mathrm{y} / \mathrm{M}$ & Left MCA/severe & $\begin{array}{l}\text { Atherosclerotic } \\
\text { Shaggy aorta }\end{array}$ & MS & TAR & $\mathrm{N}$ & $\mathrm{E}$ & $\begin{array}{l}\text { Left frontal and parietal lobe, } \\
\text { bilateral cerebellar lobe }\end{array}$ & Dead \\
\hline 7 & $69 \mathrm{y} / \mathrm{M}$ & $\mathrm{N}$ & $\mathrm{AAE}, \mathrm{AR}$ & MS & ARR & $\mathrm{N}$ & $\mathrm{E}$ & $\begin{array}{l}\text { Left frontal and parietal lobe, } \\
\text { right temporal lobe }\end{array}$ & Alive \\
\hline 8 & $71 \mathrm{y} / \mathrm{F}$ & $\begin{array}{l}\text { Bilateral ICA/severe } \\
\text { and moderate }\end{array}$ & $\begin{array}{l}\text { Atherosclerotic } \\
\text { Shaggy aorta }\end{array}$ & $\begin{array}{l}\text { MS through } \\
\text { L-incision }\end{array}$ & TAR & $\mathrm{N}$ & $\mathrm{E}$ & $\begin{array}{l}\text { Bilateral temporal and } \\
\text { occipital and cerebellar } \\
\text { lobe, left frontal lobe }\end{array}$ & Alive \\
\hline
\end{tabular}

Case 2: The patient was comatose after surgery. Continuous hemodialysis was initiated because of deterioration of renal function on day 2. After 6 hours of continuous hemodialysis, blood pressure rapidly decreased and the patient developed grand mal seizures. There were no findings of cardiac tamponade or circulatory collapse due to postoperative hemorrhage. Unfortunately, he died of unknown cause despite high-quality cardiopulmonary resuscitation. $C I A D$, Carotid or intracranial artery disease; $E T$, elephant trunk; $Y$, yes; $M$, male; ICA, internal carotid artery; $M S$, median sternotomy; $T A R$, total arch replacement; $N$, none; $E$, embolic; $A A E$, annuloaortic ectasia; $A R$, aortic valve regurgitation; $A R R$, aortic root repair; $T 6-9,6$ th to 9 th thoracic vertebrae; $M C A$, middle cerebral artery; $F$, female.

findings are highly compatible with results of the present study. Anatomic evaluation, such as carotid ultrasonography or MRA, can never evaluate cerebral perfusion reserve. Understandably, given the impaired cerebral perfusion reserve (ie, misery perfusion) in patients with obstructive CIAD, prophylactic carotid or cerebral intervention should be performed before OAAS.

The mechanisms underlying the development of ischemic stroke after cardiovascular surgery are multifactorial. Okada and colleagues ${ }^{24}$ showed that $11(5.8 \%)$ of 188 patients undergoing partial or total arch replacement with deep HCA and SACP developed intraoperative stroke. The primary cause of stroke was embolic in 8 patients $(4.3 \%)$ (multiple: 5; solitary: 3$)$ and ischemic in 4 patients $(2.1 \%) .{ }^{24}$ These

TABLE 4. Risk factors for in-hospital mortality in univariate analysis

\begin{tabular}{lcc}
\hline \multirow{2}{*}{\multicolumn{1}{c}{ Variables }} & \multicolumn{2}{c}{ Univariate } \\
\cline { 2 - 3 } & OR $(\mathbf{9 5} \% \mathbf{C I})$ & $\boldsymbol{P}$ value \\
\hline Age & $0.9(0.79-0.99)$ & .03 \\
Male & $3.2(0.5-60.89)$ & .23 \\
CPB time (min) & $0.98(0.97-0.99)$ & .02 \\
Coronary ischemic time (min) & $0.99(0.98-1.01)$ & .56 \\
HCA time (min) & $0.97(0.94-0.99)$ & .04 \\
SACP time (min) & $0.98(0.97-0.99)$ & .03 \\
Lowest rectal temperature $\left({ }^{\circ} \mathrm{C}\right)$ & $1.2(0.73-2.18)$ & .45 \\
Operation time (min) & $0.996(0.99-1.00)$ & .22 \\
\hline OR, Odion
\end{tabular}

OR, Odds ratio; $C I$, confidence interval; $C P B$, cardiopulmonary bypass; $H C A$, hypothermic circulatory arrest; $S A C P$, selective antegrade cerebral perfusion. findings are comparable to the postsurgical outcomes reported in the current article. In the present study, patients with CIAD had significantly more advanced aortic atherosclerosis than those without. Moreover, shaggy aorta was identified as a significant determinant of neurologic morbidity in both univariate and multivariate analyses, and all permanent strokes were due to multiple atherothrombotic emboli. Therefore, these findings suggest that CIAD is a surrogate marker of advanced atherosclerosis. Ulcerated plaques in the carotid artery or severe aortic atherothrombosis are potential embolic sources for ischemic stroke. Particularly, when SACP is used for brain protection, an ulcerated carotid plaque can lead to embolic events. Therefore, the preoperative anatomic evaluation of atherosclerotic vessels using ultrasonography or MRA also is highly useful for the prevention of ischemic stroke in OAAS.

TNDs are subtle and diffuse global injuries undetectable by conventional imaging methods. The occurrence of TND in the present study appears high compared with other reported results, which range from $1.5 \%$ to $9.3 \% .^{25-27}$ Our incidence of TND might be overestimated because the judgment is based on medical records alone. It should be noted that significant variation exists in the definition and assessment of TND, which may confound these findings. TND is believed to be related to the adequacy and type of cerebral protection during the period of 
TABLE 5. Risk factors for permanent stroke in univariate analysis

\begin{tabular}{lcc}
\hline & \multicolumn{2}{c}{ Univariate } \\
\cline { 2 - 3 } \multicolumn{1}{c}{ Variables } & OR $(\mathbf{9 5} \% \mathbf{C I})$ & $\boldsymbol{P}$ value \\
\hline Age & $1.0(0.93-1.05)$ & .89 \\
Male & $3.8(0.65-70.89)$ & .16 \\
CIAD & $7.2(1.70-36.52)$ & .008 \\
Shaggy aorta & $15.6(3.41-109.72)$ & .0003 \\
Type of aneurysm (atherosclerotic) & $1.3(0.30-9.26)$ & .73 \\
Total arch replacement & $0.9(0.20-6.41)$ & .92 \\
Concomitant heart procedures & $3.4(0.81-17.06)$ & .09 \\
CPB time (min) & $0.98(0.97-0.99)$ & .006 \\
Coronary ischemic time (min) & $0.99(0.98-1.01)$ & .29 \\
HCA time (min) & $1.0(0.97-1.04)$ & .83 \\
SACP time (min) & $0.99(0.98-1.01)$ & .45 \\
Lowest rectal temperature $\left({ }^{\circ} \mathrm{C}\right)$ & $1.3(0.81-2.33)$ & .27 \\
Operation time $(\min )$ & $0.99(0.99-1.00)$ & .15 \\
\hline
\end{tabular}

$O R$, Odds ratio; $C I$, confidence interval; $C I A D$, carotid or intracranial artery disease; $C P B$, cardiopulmonary bypass; $H C A$, hypothermic circulatory arrest; $S A C P$, selective antegrade cerebral perfusion.

circulatory arrest. ${ }^{11,15,28} \mathrm{Hagl}$ and colleagues ${ }^{28}$ reported a higher rate of TND with RCP than with SACP in a group of 91 patients who required a cerebral protection time between 40 and 80 minutes. Furthermore, RCP resulted in no reduction of TNDs compared with deep HCA alone. However, total cerebral protection time in OAAS exceeding 80 minutes, even with SACP, increased the occurrence of TNDs. ${ }^{28}$ In the seminal study by Svensson and colleagues ${ }^{29}$ the importance of evaluating postoperative neurologic function using both brain imaging and neurocognitive testing was reported in a randomized trial comparing SACP and RCP during HCA. Neurocognitive decline without changes in brain imaging or clinical neurologic events may be due to microembolization from the diseased aorta or CIAD. Preoperative craniocervical and aortic screening combined with careful antiembolic procedures during surgery are important for reducing the occurrence of stroke.

As for arterial cannulation, the axillary artery not only provides antegrade arterial perfusion during CPB but also allows for continuous antegrade cerebral perfusion during HCA, minimizing global cerebral ischemia. Bilateral axillary artery perfusion especially has positive effects on the maintenance of uniform circulation in both hemispheres in cases of incomplete circle of Willis, avoidance of spinal cord ischemia, and prevention of arterial complications associated with insufficient unilateral perfusion in patients with small physiques. ${ }^{30,31}$ Because of decreases in the velocity of each inflow site and thus a reduced risk of detachment of atherosclerotic debris, ${ }^{12,13}$ bilateral axillary artery plus unilateral femoral artery perfusion through side grafts is our standard perfusion approach in OAAS. During OAAS in patients with shaggy aorta, the flow rate from the femoral artery is adjusted by a clamp forceps to avoid retrograde atheromatous embolization from the descending thoracic aorta. We believe that the anastomosis of prosthetic grafts in sites far from the diseased aorta or arch vessels and meticulous de-airing are crucially important to avoid neurologic morbidity (Video 1).

Japanese guidelines have imposed strict criteria on using brain perfusion SPECT with acetazolamide because of

TABLE 6. Risk factors for neurologic morbidity in univariate and multivariate analyses

\begin{tabular}{|c|c|c|c|c|}
\hline \multirow[b]{2}{*}{ Variables } & \multicolumn{2}{|c|}{ Univariate } & \multicolumn{2}{|c|}{ Multivariate: c-index 0.80} \\
\hline & OR $(95 \%$ CI $)$ & $P$ value & OR $(95 \%$ CI $)$ & $P$ value \\
\hline Age & $0.96(0.93-0.99)$ & .044 & & \\
\hline Male & $2.3(1.01-6.12)$ & .046 & & \\
\hline Obesity & $1.1(0.36-3.07)$ & .81 & & \\
\hline COPD & $2.6(1.11-5.67)$ & .03 & & \\
\hline Previous cerebrovascular accident & $4.5(2.04-9.93)$ & .0002 & $5.0(2.07-12.42)$ & .0004 \\
\hline CIAD & $2.9(1.28-6.38)$ & .01 & & \\
\hline Peripheral arterial disease & $1.9(0.79-4.25)$ & .15 & & \\
\hline Shaggy aorta & $5.8(2.57-13.06)$ & $<.0001$ & $4.2(1.58-10.98)$ & .0045 \\
\hline Type of aneurysm (atherosclerotic) & $1.6(0.71-3.98)$ & .27 & & \\
\hline Total arch replacement & $1.6(0.66-4.50)$ & .32 & & \\
\hline Concomitant heart procedures & $1.0(0.46-2.16)$ & .97 & & \\
\hline $\begin{array}{l}\text { Extended aortic repair through L-incision or combined } \\
\text { median sternotomy and left posterior lateral thoracotomy }\end{array}$ & $7.8(2.69-23.67)$ & .0002 & $3.1(0.76-12.20)$ & .11 \\
\hline CPB time $(\min )$ & $0.99(0.98-0.99)$ & .003 & $0.99(0.99-1.00)$ & .17 \\
\hline Coronary ischemic time (min) & $0.99(0.99-1.00)$ & .81 & & \\
\hline HCA time (min) & $0.98(0.97-1.00)$ & .06 & & \\
\hline SACP time (min) & $0.99(0.98-0.99)$ & .004 & & \\
\hline Lowest rectal temperature $\left({ }^{\circ} \mathrm{C}\right)$ & $1.01(0.79-1.31)$ & .91 & & \\
\hline Operation time (min) & $0.99(0.99-0.99)$ & .02 & & \\
\hline
\end{tabular}




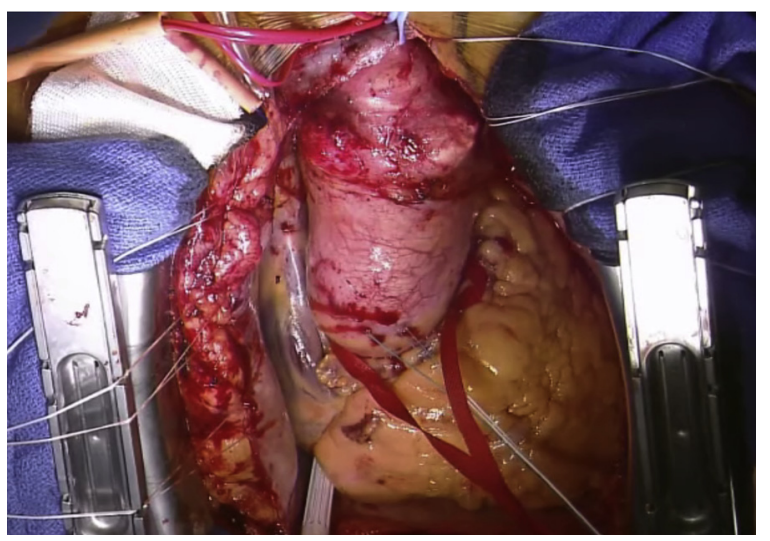

VIDEO 1. This video shows our standard procedure in a case of total arch replacement using multiple arterial perfusion approach. Video available at: http://www.jtcvsonline.org/article/S0022-5223(17)30016-8/addons.

severe complications. In light of the aforementioned data and our previous findings, ${ }^{7}$ patients with severe CIAD currently undergo brain perfusion SPECT with acetazolamide at the National Hospital Organization Kyushu Medical Center, on the basis of the judgment of the neurologists.

\section{Study Limitations}

First, it was a retrospective study from a single center. Moreover, the study is statistically limited because of the small number of patients enrolled. Second, we did not clarify what values below the lower limit in brain perfusion SPECT with acetazolamide are predictive of perioperative hemodynamic ischemic stroke during OAAS. Further studies are needed to document the reliability of preoperative intensive screening as a tool to predict perioperative hemodynamic ischemic stroke during OAAS.

\section{CONCLUSIONS}

Preoperative intensive screening of CIAD is a useful step to identify patients at higher risk of hemodynamic ischemic stroke. Advanced systemic atherosclerosis may be a crucial determinant of perioperative stroke due to atherothrombic embolization. Antiembolic measures during surgery are essential to prevent perioperative stroke.

\section{Conflict of Interest Statement}

Authors have nothing to disclose with regard to commercial support.

\section{References}

1. Salazar JD, Wityk RJ, Grega MA, Borowicz LM, Doty JR, Petrofski JA, et al. Stroke after cardiac surgery: short- and long-term outcomes. Ann Thorac Surg. 2001; 72:1195-202.

2. Miyata H, Motomura N, Tsukihara H, Takamoto S, Japan Cardiovascular Surgery Database. Risk models including high-risk cardiovascular procedures: clinical predictors of mortality and morbidity. Eur J Cardiothorac Surg. 2011; 39:667-74.
3. Likosky DS, Marrin CA, Caplan LR, Baribeau YR, Morton JR, Weintraub RM, et al. Determination of etiologic mechanisms of strokes secondary to coronary artery bypass graft surgery. Stroke. 2003;34:2830-4.

4. Cahan MA, Killewich LA, Kolodner L, Powell CC, Metz M, Sawyer R, et al. The prevalence of carotid artery stenosis in patients undergoing aortic reconstruction. Am J Surg. 1999;178:194-6.

5. Strandgaard S, Paulson OB. Cerebral autoregulation. Stroke. 1984;15:413-6.

6. Baron JC, Bousser MG, Rey A, Guillard A, Comar D, Castaigne P. Reversal of focal "misery-perfusion syndrome" by extra-intracranial arterial bypass in hemodynamic cerebral ischemia. A case study with 150 positron emission tomography. Stroke. 1981;12:454-9.

7. Imasaka K, Yasaka M, Tayama E, Tomita Y. Obstructive carotid and/or intracranial artery disease rarely affects the incidence of haemodynamic ischaemic stroke during cardiac surgery: a study on brain perfusion single-photon emission computed tomography with acetazolamide. Eur J Cardiothorac Surg. 2015;48:739-46.

8. Randomised trial of endarterectomy for recently symptomatic carotid stenosis: final results of the MRC European Carotid Surgery Trial (ECST). Lancet. 1998:351:1379-87.

9. Menke J. Diagnostic accuracy of contrast-enhanced MR angiography in severe carotid stenosis: meta-analysis with metaregression of different techniques. Eur Radiol. 2009;19:2204-16.

10. Rothwell PM, Gutnikov SA, Warlow CP. European Carotid Surgery Trialist's Collaboration. Reanalysis of the final results of the European Carotid Surgery Trial. Stroke. 2003;34:514-23.

11. Svensson LG, Blackstone EH, Rajeswaran J, Sabik JF III, Lytle BW, GonzalezStawinski G, et al. Does the arterial cannulation site for circulatory arrest influence stroke risk? Ann Thorac Surg. 2004;78:1274-84.

12. Muehrcke DD, Cornhill JF, Thomas JD, Cosgrove DM. Flow characteristics of aortic cannulae. J Card Surg. 1995;10(4 Suppl):514-9.

13. Groom RC, Hill AG, Kuban B, Oneill W, Akl BF, Speir AM, et al. Aortic cannula velocimetry. Perfusion. 1995;10:183-8.

14. Tominaga R, Kurisu K, Ochiai Y, Nakashima A, Masuda M, Morita S, et al. Total aortic arch replacement through the L-incision approach. Ann Thorac Surg. 2003; $75: 121-5$.

15. Ergin MA, Galla JD, Lansman SL, Quintana C, Bodian C, Griepp RB Hypothermic circulatory arrest in operations on the thoracic aorta. Determinations of operative mortality and neurologic outcome. J Thorac Cardiovasc Surg. 1994;107:788-97.

16. Hollier LH, Kazmier FJ, Ochsner J, Bowen JC, Procter CD. "Shaggy" aorta syndrome with atheromatous embolization to visceral vessels. Ann Vasc Surg. 1991;5:439-44.

17. Katz ES, Tunick PA, Rusinek H, Ribakove G, Spencer FC, Kronzon I. Protruding aortic atheromas predict stroke in elderly patients undergoing cardiopulmonary bypass: experience with intraoperative transesophageal echocardiography J Am Coll Cardiol. 1992;20:70-7.

18. Blackstone EH. Sufficient data. J Thorac Cardiovasc Surg. 2016;152:1235-6.

19. Wintermark M, Sesay M, Barbier E, Borbély K, Dillon WP, Eastwood JD, et al. Comparative overview of brain perfusion imaging techniques. Stroke. 2005;36: e83-99.

20. Barber PA, Consolo HK, Yang Q, Darby DG, Desmond PM, Lichtenstein M, et al. Comparison of MRI perfusion imaging and single photon emission computed tomography in chronic stroke. Cerebrovasc Dis. 2001;11:128-36.

21. Neri E, Sassi C, Barabesi L, Massetti M, Pula G, Buklas D, et al. Cerebral autoregulation after hypothermic circulatory arrest in operations on the aortic arch. Ann Thorac Surg. 2004;77:72-9.

22. Spielvogel D, Kai M, Tang GHL, Malekan R, Lansman SL. Selective cerebral perfusion: a review of the evidence. J Thorac Cardiovasc Surg. 2013;145: S59-62.

23. Urbanski PP, Lenos A, Blume JC, Ziegler V, Griewing B, Schmitt R, et al. Does anatomical completeness of the circle of Willis correlate with sufficient cross-perfusion during unilateral perfusion? Eur J Cardiothorac Surg. 2008;33:402-8.

24. Okada T, Shimamoto M, Yamazaki F, Nakai M, Miura Y, Itonaga T, et al. Insights of stroke in aortic arch surgery: identification of significant risk factors and surgical implication. Gen Thorac Cardiovasc Surg. 2012;60:268-74.

25. Halkos ME, Kerendi F, Myung R, Kilgo P, Puskas JD, Chen EP. Selective antegrade cerebral perfusion via right axillary artery cannulation reduces morbidity and mortality after proximal aortic surgery. J Thorac Cardiovasc Surg. 2009;138:1081-9.

26. Leshnower BG, Kilgo PD, Chen EP. Total arch replacement using moderate hypothermic circulatory arrest and unilateral selective antegrade cerebral perfusion. J Thorac Cardiovasc Surg. 2014;147:1488-92. 
27. Angeloni E, Melina G, Refice SK, Roscitano A, Capuano F, Comito C, et al. Unilateral versus bilateral antegrade cerebral protection during aortic surgery: an updated meta-analysis. Ann Thorac Surg. 2015;99:2024-31.

28. Hagl C, Ergin MA, Galla JD, Lansman SL, McCullough JN, Spielvogel D, et al. Neurologic outcome after ascending aorta-aortic arch operations: effect of brain protection technique in high-risk patients. J Thorac Cardiovasc Surg. 2001;121: 1107-21

29. Svensson LG, Blackstone EH, Apperson-Hansen C, Ruggieri PM, Ainkaran P, Naugle RI, et al. Implications from neurologic assessment of brain protection for total arch replacement from a randomized study. J Thorac Cardiovasc Surg. 2015;150:1140-7.
30. Kurisu K, Hisahara M, Ando Y, Tominaga R. Bilateral axillary perfusion to reduce brain damage during cardiopulmonary bypass. J Card Surg. 2010;25:139-42.

31. Kurisu K, Ochiai Y, Hisahara M, Tanaka K, Onzuka T, Tominaga R. Bilateral axillary arterial perfusion in surgery on thoracic aorta. Asian Cardiovasc Thorac Ann. 2006;14:145-9.

Key Words: open aortic arch surgery, carotid or intracranial atherosclerosis, perioperative stroke, craniocervical screening, SPECT with acetazolamide

Readers who found these articles interesting may also like to read the following papers found in recent and future issues of our sister publications, Seminars in Thoracic and Cardiovascular Surgery and Operative Techniques in Thoracic and Cardiovascular Surgery!

\section{Acquired: Aortic Disease}

Extent II Thoracoabdominal Aortic Aneurysm Repair: How I Do It Joseph S. Coselli. Semin Thoracic Surg 2016: 221-237.

Phase of Care Mortality Analysis: A Unique Method for Comparing Mortality Differences Among Transcatheter Aortic Valve Replacement and Surgical Aortic Valve Replacement Patients Todd C. Crawford. Semin Thoracic Surg 2016: 245-252.

Aortic Root Surgery: Does High Surgical Volume and a Consistent Perioperative Approach Improve Outcome? Rajdeep Bilkhu. Semin Thoracic Surg 2016: 302-309.

Cut Well, Sew Well, Do Well ... And Do It Often! Leonard N. Girardi. Semin Thoracic Surg 2016: 310-311.

Endovascular Repair of Type a Aortic Dissection: Current Experience and Technical Considerations Joshua D. Horton. Semin Thoracic Surg 2016: 312-317.

Endovascular Repair of Type a Dissection: Just Because we can does that Mean we should? Leonard N. Girardi. Semin Thoracic Surg 2016: 318-319.

Sutureless Aortic Valves: Combining the Best or the Worst? Kareem Bedeir. Semin Thoracic Surg 2016: 341-352.

The Impact of Initiation of a TAVR Program on the Treatment of Severe Aortic Stenosis Niv Ad. Semin Thoracic Surg 2016: 353-360. Implementing the TAVR heart team: Complementary, Not Competitive, to SAVR volume And Outcomes Xiaoying Lou. Semin Thoracic Surg 2016: 361-362.

Stentless Versus Stented Aortic Valve Bioprostheses in the Small Aortic Root LW Wollersheim. Semin Thoracic Surg 2016: 390-397.

The Narrow Aortic Root. A Continuing Surgical Challenge Manuel J Antunes. Semin Thoracic Surg 2016: 398-399.

Transapical Cannulation Through a Transcatheter Aortic Valve Implantation Valve: A Novel Approach for Cardiogenic Collapse Louis Philippe Tremblay. Semin Thoracic Surg 2016: 400-402.

Preparation for Transapical Arterial Access and Perfusion is Essential for Transcatheter Aortic Valve Replacement Richard J. Shemin. Semin Thoracic Surg 2016: 403.

Comparison of Aortic Annulus Dimension after Aortic Valve neo-cuspidization with valve replacement and normal valve Yoshitaka Yamamoto. Semin Thoracic Surg 2016: In press.

Malperfusion in Type A Dissection: Consider Reperfusion First. Joshua B. Goldberg. Semin Thoracic Surg 2016: In press.

Early Outcomes of Acute Retrograde Dissection From the International Registry of Acute Aortic Dissection Foeke J.H. Nauta. Semin Thoracic Surg 2016: In press.

Management of Symptomatic Severe Aortic Stenosis in Patient With Very Severe Chronic Obstructive Pulmonary Disease Amgad Mentias. Semin Thoracic Surg 2016: In press.

Similar Survival After Repair vs Replacement for Ischemic Mitral Regurgitation Hisato Takag. Semin Thoracic Surg 2016: In press.

Immediate Spinal Cord Collateral Blood Flow During Thoracic Aortic Procedures: The Role of Epidural Arcades Fabian A. Kari. Semin Thoracic Surg 2016: 378-387.

Visceral Malperfusion in Aortic Dissection: The Michigan Experience Arnoud V. Kamman. Semin Thoracic Surg 2016: In press. 